\title{
Nutritional and Physicochemical Characterization of Vegetable Fibres in Order to Obtain Gelled Products ${ }^{+}$
}

\author{
Ana Teresa Noguerol, Marta Igual and $M^{a}$ Jesús Pagán-Moreno *
}

Citation: Noguerol, A.T.; Igual, M.; Pagán-Moreno, M.J. Nutritional and Physicochemical Characterization of Vegetable Fibres in Order to Obtain Gelled Products. Proceedings 2021 70, 23. https://doi.org/10.3390/ foods_2020-07686

Published: 9 November 2020

Publisher's Note: MDPI stays neutral with regard to jurisdictional claims in published maps and institutional affiliations.

\section{(i)}

Copyright: $\left({ }^{\circ} 2020\right.$ by the authors. Licensee MDPI, Basel, Switzerland. This article is an open access article distributed under the terms and conditions of the Creative Commons Attribution (CC BY) license (http://creativecommons.org/licenses/by/4.0/).
Food Investigation and Innovation Group, Food Technology Department, Universitat Politècnica de València, Camino de Vera s/n, 46022 Valencia, Spain; annome@etsiamn.upv.es (A.T.N.); marigra@upvnet.upv.es (M.I.)

* Correspondence: jpagan@tal.upv.es; Tel.: +34-96-387-7000 (ext. 73621)

† Presented at the 1st International Electronic Conference on Food Science and Functional Foods, 10-25 November 2020; Available online: https://foods_2020.sciforum.net/.

\begin{abstract}
The aim of this research was to evaluate the nutritional and physicochemical properties of two combinations of vegetable fibres (FBPC: bamboo, Psyllium, and citric fibre, and FPESB: pea, cane sugar, and bamboo fibre) and the possibility of using them as a thickener or gelling agent in food. To determine the technological, nutritional, and physical parameters the following analyses were carried out: water holding capacity, water retention capacity, swelling, fat absorption capacity, solubility, particle size, moisture, hygroscopicity, water activity, bulk density, porosity, antioxidant activity, phenolic compounds, and minerals content. In addition, gels were prepared at concentrations 1 to $7 \%$ at $5{ }^{\circ} \mathrm{C}$ and analysed at $25{ }^{\circ} \mathrm{C}$ before and after a treatment at $65{ }^{\circ} \mathrm{C}$ for $20 \mathrm{~min}$. Back extrusion test, $\mathrm{pH}$, and colour were carried out. As results, both samples showed significant differences in all tested parameters. Hydration properties of FBPC were higher than in FPESB, but at the functional level, high values were found in FPESB. Moreover, FPESB was a source of minerals with an important content of Fe. In gels, significant differences in textural properties were found between samples and also due to the treatment used but further studies are needed to explore their use in the development of functional food products.
\end{abstract}

Keywords: vegetable fibres; minerals; antioxidant capacity; gelling agent

\section{Introduction}

There is an increase in consumers' interest in health and the sustainability aspects of their way of living and their diet. They demand more natural and less processed foods that are made using ingredients which are not perceived negatively [1].

It is a well-known fact that hydrocolloids change the physical properties of a solution to form gels, or enable thickening, emulsification, coating, stabilization, and also provide viscosity and play a role in developing food with high satiating capacity [2]. In addition to functional qualities, hydrocolloids have also received enthusiastic countenance due largely to the dietary fibre aspect of food hydrocolloids [2]. This aspect is important for the beneficial effects on health as a dietary fibre (DF), as well as a prebiotic ingredient and its technological attributes such as water binding, gelling, and structure building. Therefore, it could be used as a low-calorie sweetener, fat replacer, or texture modifier [2,3].

For these reasons, designing future food structures by structuring food colloids such as fibre is of great theoretic and application value, for example, for its use in functional food products aimed at elderly people with swallowing problems, special food products for diabetes, or artificial plant-based meats for vegan and vegetarians [4].

The main purpose of this research was to evaluate the nutritional and physicochemical properties of two different combination of vegetable fibres and the possibility of using them as a thickener or gelling agent in food. 


\section{Materials and Methods}

\subsection{Raw Materials}

Both samples used in this study were a combination of DFs supplied by the company Productos Pilarica S.A., Paterna, Spain. FBPC a combination of bamboo, Psyllium, and citric fibre, and FPESB a combination of pea, cane sugar, and bamboo fibre.

\subsection{Physicochemical Analysis}

Moisture $\left(\mathrm{x}_{\mathrm{w}}\right)$ ( $\mathrm{g}$ water/100 $\mathrm{g}$ sample) was determined by vacuum oven drying (Vaciotem, J.P. Selecta, Spain) at $70{ }^{\circ} \mathrm{C}$ until constant weight.

Water activity (aw) of the samples was analysed by the AquaLab PRE LabFerrer equipment (Pullman, Washington, DC, USA).

Hygroscopicity $(\mathrm{Hg})$ was determined according to Cai and Corke [5].

The samples' particle size distribution was determined according to the ISO13320 normative (AENOR 2009) using a particle size analyser (Malvern Instruments Ltd., Mastersizer 2000, Worcestershire, UK) equipped with a dry sample dispersion unit (Malvern Instruments Ltd., Scirocco 2000, Malvern, UK). The particle size distribution was characterised by the volume mean diameter ( $\mathrm{D}[4.3])$.

The porosity $(\varepsilon)$ was determined from the true $(\varrho)$ and bulk ( $(\mathrm{b})$ densities according to Agudelo et al. [6] with slight modifications.

\subsection{Hydration Properties}

Water-holding capacity (WHC) and water retention capacity (WRC) were as described by Raghavendra et al. [7] and Chantaro et al. [8], respectively.

Swelling water capacity (SWC) and fat adsorption capacity (FAC) were as described by Navarro-González et al. [9] with minor modifications.

Water solubility index (WSI) was analysed according to the method of Mahdavi et al. [10] with small modifications.

\subsection{Antioxidant Capacity and Phenolic Compounds}

Antioxidant capacity (AOA) was assessed using the DPPH method following Igual et al. [11] methodology.

Total phenol content (PC) was carried out according to Agudelo et al. [6].

\subsection{Mineral Analysis}

The multi-mineral determination was analysed using inductively coupled plasma optical emission spectrometer, model 700 Series ICP-OES from Agilent Technologies (Santa Clara, CA, USA), with axial viewing and a charge coupled device detector [12]. Mineral composition (macro and microelements) were expressed as mg/100 g.

\subsection{Gel Preparation}

The samples were dissolved in cold water $\left(5^{\circ} \mathrm{C}\right)$ during $30 \mathrm{~min}$ at concentrations 1 , $2,3,4,5,6$, and 7 . Samples were divided in two batches. One of them was directly stored $24 \mathrm{~h}$ at $5{ }^{\circ} \mathrm{C}$ until the stabilisation of the gels. However, the other batch was heated at 65 ${ }^{\circ} \mathrm{C}$ for $20 \mathrm{~min}$ before being stored $24 \mathrm{~h}$ at $5^{\circ} \mathrm{C}$. All samples were analysed after this storage at $25^{\circ} \mathrm{C}$.

\subsection{Gel Analysis: $p H$, Colour and Texture}

The $\mathrm{pH}$ of the gel samples was measured using a $\mathrm{pH}$-meter Crison MultiMeter MM 41 (Hach Lange, Barcelona, Spain).

To determine the colour of the gels, translucency and $C \mathrm{IE}^{*} \mathrm{~L}^{*} \mathrm{a}^{*} \mathrm{~b}^{*}$ colour were carried out according to García-Segovia et al. [12]. 
Textural characteristics were evaluated by using a TA-XT2 Texture Analyser (Stable Micro Systems Ltd., Godalming, UK). The back extrusion test was performed following the method described by Cevoli et al. [13] with minor modifications.

\subsection{Statistical Analysis}

Analysis of variance (ANOVA), with a confidence level of $95 \%(p<0.05)$, was applied to evaluate the differences among samples, using Statgraphics Centurion XVII Software, version 17.2.04.

\section{Results and Discussion}

Table 1 shows the physicochemical and hydration properties of samples studied. In general, significant $(p<0.05)$ differences were found between samples, except for Hg. FBPC showed higher moisture than FPESB, these values were lower than those found by de Moraes Crizel [5] for orange fibres. The values of aw were within the ideal range of 0.11 to 0.40 [5].

Table 1. Physicochemical and hydration properties of fibres tested.

\begin{tabular}{lcc}
\hline & \multicolumn{2}{c}{ Mix of Vegetable Fibres } \\
\cline { 2 - 3 } & FBPC & FPESB \\
\hline Moisture (\%) & $6.676 \pm 0.104^{\mathrm{a}}$ & $5.7 \pm 0.3^{\mathrm{b}}$ \\
Water activity (aw) & $0.3590 \pm 0.0012^{\mathrm{a}}$ & $0.342 \pm 0.002^{\mathrm{b}}$ \\
Hg (g water/100 g dry solid) & $26.7 \pm 0.7^{\mathrm{a}}$ & $27.3 \pm 0.2^{\mathrm{a}}$ \\
Bulk density (g/L) & $489 \pm 17^{\mathrm{a}}$ & $354 \pm 10^{\mathrm{b}}$ \\
Porosity & $69.22 \pm 0.95^{\mathrm{b}}$ & $77.51 \pm 0.12^{\mathrm{a}}$ \\
D[4,3] ( $\mu \mathrm{m})$ & $142.6 \pm 0.3^{\mathrm{b}}$ & $156 \pm 2^{\mathrm{a}}$ \\
WHC $(\mathrm{g}$ water/g sample) & $21.197 \pm 0.097 \mathrm{a}$ & $6.18 \pm 1.03^{\mathrm{b}}$ \\
WRC (g water/g sample) & $8.7 \pm 0.8^{\mathrm{a}}$ & $4.9 \pm 0.3^{\mathrm{b}}$ \\
SWC (mL water/g sample) & $8 \pm 2 \mathrm{a}$ & $9.2 \pm 0.8^{\mathrm{a}}$ \\
FAC (g oil/g sample) & $1.44 \pm 0.03 \mathrm{~b}$ & $1.91 \pm 0.03 \mathrm{a}$ \\
WSI (\%) & $19.4 \pm 0.2 \mathrm{a}$ & $6.28 \pm 0.02 \mathrm{~b}$ \\
PC (mg gallic/100 g sample) & $52.6 \pm 0.7 \mathrm{~b}$ & $64 \pm 7 \mathrm{a}$ \\
AOA (mg trolox/100 g sample) & $12.4 \pm 0.8 \mathrm{~b}$ & $19.7 \pm 0.7 \mathrm{a}$ \\
\hline
\end{tabular}

Hg: hygroscopicity; WHC: water holding capacity; WRC: water retention capacity; SWC: swelling capacity; WSI: solubility; FAC: fat absorption capacity; PC: phenolic compounds; AOA: antioxidant activity. Results are the mean of three determination \pm standard deviation. Different letter in the same row are significantly different as determined by LSD test $(p<0.05)$.

The lowest bulk density was showed by FPESB, this value was lower than that obtained by Lan et al. [14] for DFs from Polygonatum odoratum and cellulose. Particle size distribution of samples was similar (Figure 1), but the sample FPESB showed a high D [4,3] (Table 1).

FBPC presented greater values of almost hydration properties such as WHC, WRC, and SWC, but FPESB showed a high solubility and fat absorption.

The sample which showed great antioxidant activity and phenols content was FPESB, although these values were lower than those obtained by Navarro-González et al. [11] for tomato peel fibre.

Table 2 showed mineral content of both DFs. In general, FPESB showed a greater mineral content. Values that should be highlighted were Fe content, and also other trace elements such as manganese and zinc, which was only detected in this sample. The values for $\mathrm{K}, \mathrm{Ca}, \mathrm{Mg}$, and Fe were similar to some obtained by $\mathrm{Ma}$ and $\mathrm{Mu}$ [15] for DFs obtained from de-oiled cumin. 


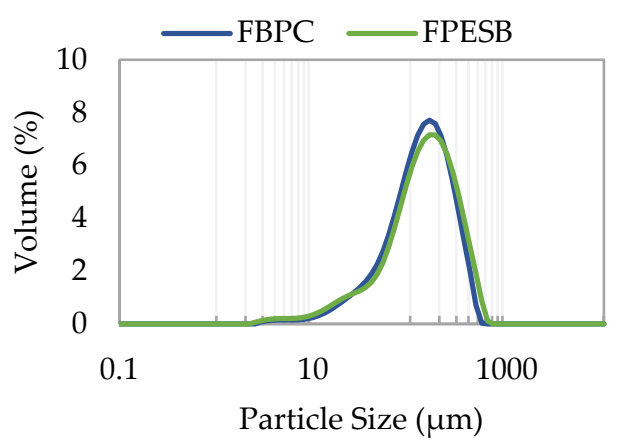

Figure 1. Volume of particle size distributions (representative curves) of fibres studied.

Table 2. Mineral content of samples expressed in $\mathrm{mg} / 100 \mathrm{~g}$.

\begin{tabular}{ccc}
\hline & \multicolumn{2}{c}{ Mix of Vegetable Fibres } \\
\cline { 2 - 3 } & FBPC & FPESB \\
\hline $\mathrm{P}$ & $7.9 \pm 0.7^{\mathrm{b}}$ & $32.9 \pm 1.4^{\mathrm{a}}$ \\
$\mathrm{K}$ & $167 \pm 14^{\mathrm{a}}$ & $141 \pm 7^{\mathrm{b}}$ \\
$\mathrm{Na}$ & $96 \pm 3^{\mathrm{b}}$ & $340 \pm 16^{\mathrm{a}}$ \\
$\mathrm{Mg}$ & $40 \pm 4^{\mathrm{b}}$ & $60 \pm 3^{\mathrm{a}}$ \\
$\mathrm{Zn}$ & $3.706 \pm 1.002^{\mathrm{b}}$ & $107 \pm 4^{\mathrm{a}}$ \\
$\mathrm{Fe}$ & $-\mathrm{b}$ & $0.58 \pm 0.03^{\mathrm{a}}$ \\
$\mathrm{Mn}$ & $1.6 \pm 0.3^{\mathrm{b}}$ & $4.2 \pm 0.5^{\mathrm{a}}$ \\
\hline
\end{tabular}

Results are the mean of three determination \pm standard deviation. Different letter in the same row are significantly different as determined by LSD test $(p<0.05)$.

Table 3 shows results of the gel's analysis. An interaction between samples and concentrations was observed for both the unheated and heated samples. A decrease in $\mathrm{pH}$ was shown as the concentration increases, this decrease being more intense in the case of the FPESB sample. Furthermore, for both samples, an interaction between temperature and concentrations was also observed with a $\mathrm{pH}$ greater decrease in unheated concentrations.

For both samples unheated and heated colour coordinates $\left(\mathrm{L}^{*}, \mathrm{a}^{*}\right.$, and $\left.\mathrm{b}^{*}\right)$ were increasing as the DFs concentration was increasing (Table 3), the values of FBPC were always significantly $(p<0.05)$ higher than those for FPESB. Only in the case of FPESB, for $\mathrm{a}^{*}$ and $\mathrm{b}^{*}$, an interaction was observed between concentrations and temperature, showing samples unheated (FPESB) for $1-3 \%$ concentration a significantly $(p<0.05)$ greater increase than heated (65FPESB).

Back extrusion assay showed that not only the consistency and firmness of gels were increasing as gel's DFs concentration increased, but also the viscosity and cohesiveness in both samples (Table 3). For both samples and for all texture parameters, an interaction was shown between concentration and temperature. A significant $(p<0.05)$ increase in all parameters from concentration $3 \%$ was observed. In this way, the sample which presented the greater consistency was 65FBPC (7\%). The values of consistency, firmness, and cohesiveness were higher in 65FBPC $(4 \%)$, but this sample presented lower viscosity than that found by Cevoli et al. [13] for xanthan gum (4\%). Although comparing it with 65FPESB $(4 \%)$, both showed similar consistency and cohesiveness, 65FPESB $(4 \%)$ presented a higher strength and lower viscosity. In short, the physicochemical, functional, and nutritional properties of both combinations of vegetable fibres, as well as their ability to form gels, make it possible to use them to modify the texture of different foods and provide the benefits of DF consumption. 
Table 3. Results (mean \pm deviation) of gel analysis.

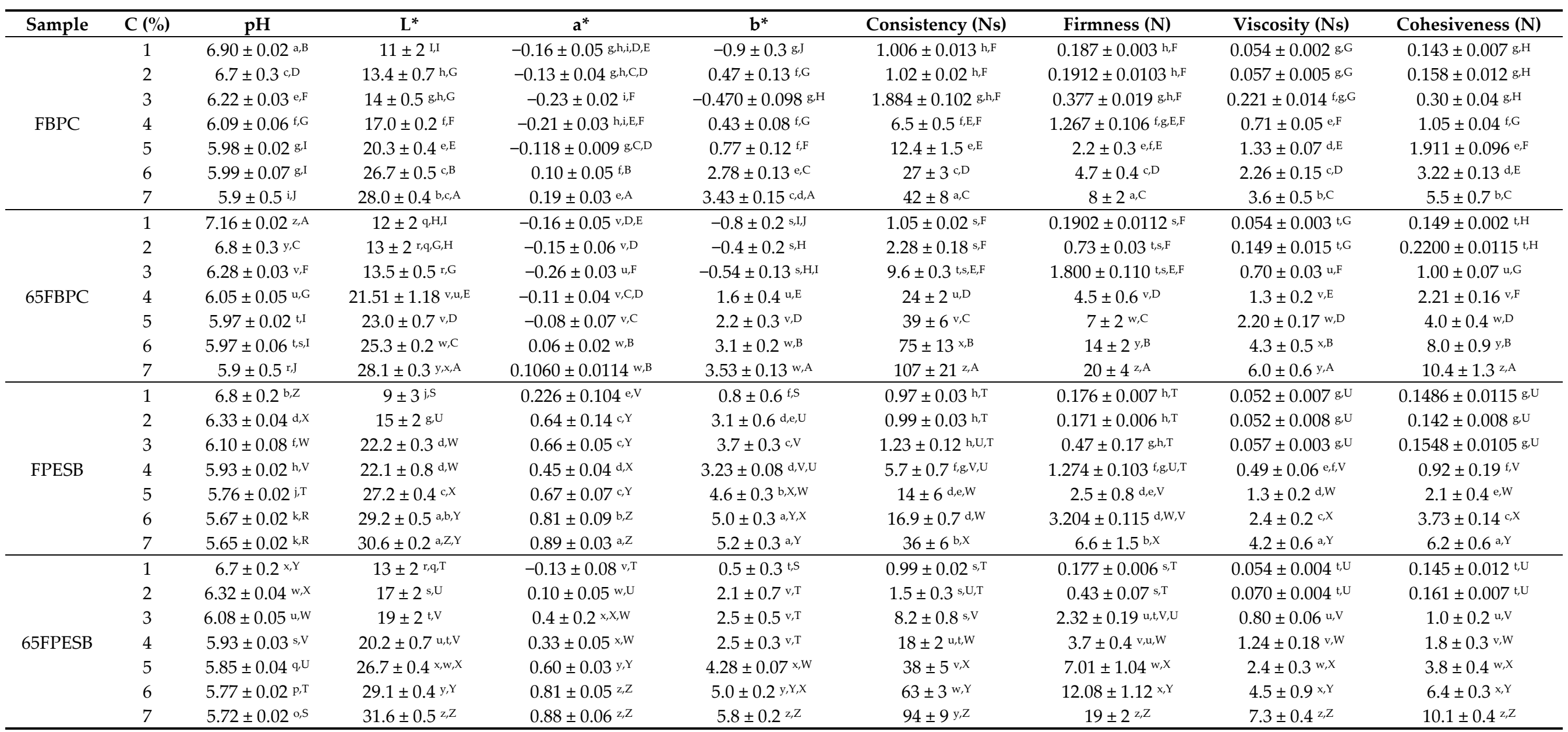

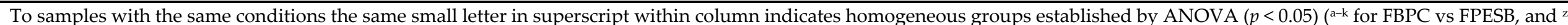

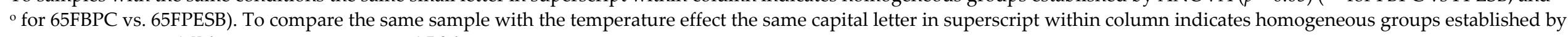
ANOVA $(p<0.05)$ (A-H for FBPC vs. 65FBPC and ${ }^{Z-S}$ for FPESB vs. 65FPESB). C: Concentration. 
Author Contributions: Conceptualization, A.T.N., M.I., and M.J.P.-M; methodology, A.T.N. and M.I.; validation, A.T.N., M.I., and M.J.P.-M.; formal analysis, A.T.N. and M.I.; investigation, A.T.N., M.I., and M.J.P.-M.; resources, M.J.P.-M.; data curation, A.T.N. and M.I.; writing-original draft preparation, A.T.N.; writing - review and editing, M.I. and M.J.P.-M.; supervision, M.J.P.-M.; project administration, M.J.P.-M. All authors have read and agreed to the published version of the manuscript.

Funding: A.T.N. received financial support by Generalitat Valenciana (program FDEGENT 2018) for her research stay at UPV.

Institutional Review Board Statement: Not applicable.

Informed Consent Statement: Not applicable.

Data Availability Statement: The data presented in this study are available on request from the corresponding author.

Acknowledgments: Authors acknowledge the company Productos Pilarica S.A. (Paterna, Spain) for supply the necessary material.

Conflicts of Interest: The authors declare no conflict of interest.

\section{References}

1. Aschemann-Witzel, J.; Varela, P.; Peschel, A.O. Consumers' categorization of food ingredients: Do consumers perceive them as 'clean label'producers expect? An exploration with projective mapping. Food Qual. Prefer. 2019, 71, 117-128.

2. Li, J.M.; Nie, S.P. The functional and nutritional aspects of hydrocolloids in foods. Food Hydrocoll. 2016, 53, 46-61.

3. De Moraes Crizel, T.; Jablonski, A.; de Oliveira Rios, A.; Rech, R.; Flôres, S.H. Dietary fiber from orange byproducts as a potential fat replacer. LWT 2013, 53, 9-14.

4. Lu, W.; Nishinari, K.; Matsukawa, S.; Fang, Y. The future trends of food hydrocolloids. Food Hydrocoll. $2020,103,105713$.

5. Cai, Y.Z.; Corke, H. Production and properties of spray-dried Amaranthus betacyanin pigments. J. Food Sci. 2000, 65, 1248-1252.

6. Agudelo, C.; Igual, M.; Camacho, M.M.; Martínez-Navarrete, N. Effect of process technology on the nutritional, functional, and physical quality of grapefruit powder. Food Sci. Technol. Int. 2017, 23, 61-74.

7. Raghavendra, S.N.; Rastogi, N.K.; Raghavarao, K.S.M.S.; Tharanathan, R.N. Dietary fiber from coconut residue: Effects of different treatments and particle size on the hydration properties. Eur. Food Res. Technol. 2004, 218, 563-567.

8. Chantaro, P.; Devahastin, S.; Chiewchan, N. Production of antioxidant high dietary fiber powder from carrot peels. LWT 2008, 41, 1987-1994.

9. Navarro-González, I.; García-Valverde, V.; García-Alonso, J.; Periago, M.J. Chemical profile, functional and antioxidant properties of tomato peel fiber. Food Res. Int. 2011, 44, 1528-1535.

10. Mahdavi, S.A.; Jafari, S.M.; Assadpour, E.; Ghorbani, M. Storage stability of encapsulated barberry's anthocyanin and its application in jelly formulation. J. Food Eng. 2016, 181, 59-66.

11. Igual, M.; García-Martínez, E.; Camacho, M.M.; Martínez-Navarrete, N. Stability of micronutrients and phytochemicals of grapefruit jam as affected by the obtention process. Food Sci. Technol. Int. 2016, 22, 203-212.

12. García-Segovia, P.; Igual, M.; Noguerol, A.T.; Martinez-Monzo, J. Use of insects and pea powder as alternative protein and mineral sources in extruded snacks. Eur. Food Res. Technol. 2020, 246, 703-712.

13. Cevoli, C.; Balestra, F.; Ragni, L.; Fabbri, A. Rheological characterisation of selected food hydrocolloids by traditional and simplified techniques. Food Hydrocoll. 2013, 33, 142-150.

14. Lan, G.; Chen, H.; Chen, S.; Tian, J. Chemical composition and physicochemical properties of dietary fiber from Polygonatum odoratum as affected by different processing methods. Food Res. Int. 2012, 49, 406-410.

15. Ma, M.M.; Mu, T.H. Effects of extraction methods and particle size distribution on the structural, physicochemical, and functional properties of dietary fiber from deoiled cumin. Food Chem. 2016, 194, 237-246. 